\title{
Neuroimaging in Focal Epilepsies: An Update
}

\section{Fokal Epilepsilerde Nörolojik Görüntüleme: Güncelleme}

\author{
Vanessa C Mendes COELHO, Marcia Elisabete MORITA, Fernando CENDES
}

Department of Neurology, University of Campinas - Unicamp, Campinas, Sp, Brazil

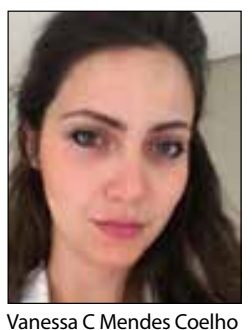

Vanessa C Mendes Coelho

\section{Summary}

Epilepsy is a common neurologic disorder with diverse etiologies. Appropriate MRI investigation has an important role in the assessment of epilepsy. Specific protocols are required for recognition of epileptogenic lesions, particularly for recognition of subtle lesions. In patients with refractory epilepsy and "normal MRI," multimodal imaging techniques are crucial in the definition of epilepsy etiology, including those that combine metabolic and functional investigation, such as fluorodeoxyglucose positron emission tomography (FDG-PET), single-photonemission computed tomography (SPECT), diffusion MRI and magnetic resonance spectroscopy (MRS). Familiarity with various protocols of imaging studies is required for optimized investigation of seizure etiology. Main features found in MRIs of patients with focal epilepsies are discussed in the present review, as are alternative protocols and techniques of imaging that may optimize neuroimaging investigation in patients with epilepsy. The findings described have a direct impact on treatment and prognosis counseling of patients with focal epilepsies. Keywords: Focal epilepsies; neuroimaging.

\section{Özet}

Epilepsi, çeşitli etiyolojileri olan yaygın bir nörolojik rahatsızlıktır. Epilepsi değerlendirmesinde uygun manyetik rezonans görüntüleme (MRG) incelemeleri önemli bir role sahiptir. Epileptojenik lezyonların, özellikle güç alıgılanılan lezyonların teşhisi için spesifik protokollere ihtiyaç vardır. Dirençli epilepsisi olan ve "normal MRG" sonuçlarına sahip hastalarda florodeoksiglikoz-pozitron emsiyon tomografisi (FG-PET), tek föton emisyon bilgisayarlı tomografi (SPECT), difüzyon MRG ve manyetik rezonans spektroskopisi (MRS) gibi metabolik ve fonksiyonel incelemeleri de birleştiren multimodal görüntüleme yöntemleri epilepsi etiyolojisini tanımlamada önem taşımaktadır. Görüntüleme yöntemlerinin farklı protokollerine aşina olmak nöbet etiyolojisinin optimize incelemesi açısından gereklidir. Biz bu çalışmada, fokal epilepsisi olan hastaların MRG incelemesinde bulunan başlıca özellikleri tartışacağız. Ayrıca, epilepsisi olan hastaların nörolojik görüntüleme ile yapılan incelemelerini en uygun hale getirebilecek farklı görüntüleme yöntemleri ve alternatif protokolleri de tartışacağız. Burada tanımlanan bulguların, fokal epilepsisi olan hastaların tedavisi ve prognoz danışmanlığı üzerine doğrudan bir etkisi olacaktır.

Anahtar sözcükler: Fokal epilepsi; nörolojik görüntüleme.

\section{Introduction}

Epilepsy is one of the most prevalent chronic neurological disorders affecting approximately 50 million people worldwide $^{[1]}$ and is characterized by the occurrence of spontaneous recurrent seizures. ${ }^{[2]}$

Many patients respond well to optimized anti-epileptic drugs (AEDs) treatment; however, seizure freedom is not always reached. Uncontrolled epilepsy markedly affects patients' quality of life and has devastating effects on cognitive function. Furthermore, it also increases the risks of sudden death. ${ }^{[3]}$ At least $30 \%$ of patients are refractory to AEDs or do not tolerate medications due to side- effects. ${ }^{[4]}$ Surgery should be considered as an important option for pharmaco-resistant epilepsy. To that end, the role of neuroimaging, mainly magnetic resonance imaging (MRI), becomes indispensable, since it is a non-invasive tool that allows us to identify lesions involved in epilepsy. It also allows us to monitor disease progression. ${ }^{[5]}$ 
This paper will review the role of neuroimaging in epilepsy, discussing the main features found in MRI of patients with focal epilepsies.

\section{Reasons for Performing MRI in Patients With Epilepsy}

When a first seizure occurs, it often refers to a bilateral convulsive seizure. The probability of recurrence is variable, with studies showing that the risk of recurrence after a first tonic-clonic seizure is around 50\% in the next year or two. ${ }^{[6,7]}$ How and when a patient with a first seizure should be imaged depends on scanner availability and the suspected cause of the seizure. ${ }^{[8]}$

In patients with well-defined genetic epilepsies or age related epilepsies (e.g. juvenile myoclonic epilepsy) the need of a MRI may be argued. However, if there is suspicion of a structural cause, an MRI should always be performed. In the setting of an acute seizure in older patients the role of neuroimaging is essential to rule out structural lesions. ${ }^{\left[{ }^{[9}\right.}$

By helping defining the etiology of epilepsy, MRI becomes an important tool for prognostic counseling and defining treatment strategy. We can, also, use MRI to monitor progression of lesions. DTI, 3D reconstructions and co-registrations are important tools in surgical planning (Figure 1).

In the research field, MRI allows us to better understand the pathophysiology of epilepsy. ${ }^{[5]}$

\section{How to Perform an MRI}

In the setting of new onset epilepsy, clinical evaluation, electroencephalographic findings and neuroimaging should be considered together when defining the probable etiology of epilepsy. Among these methods, MRI is the only one that may show the etiology of seizures. The epileptogenic lesion may be detected using routine MRI protocols. However, routine MRIs often miss smaller or subtle lesions and are considered normal. Therefore, in these cases, an optimized epilepsy protocol with adequate spatial resolution and multiplanar reformatting is essential9 (Figure 2).

Epilepsy protocols should be chosen depending on the clinical hypothesis. Suggested protocols are summarized in Tables 1, 2.

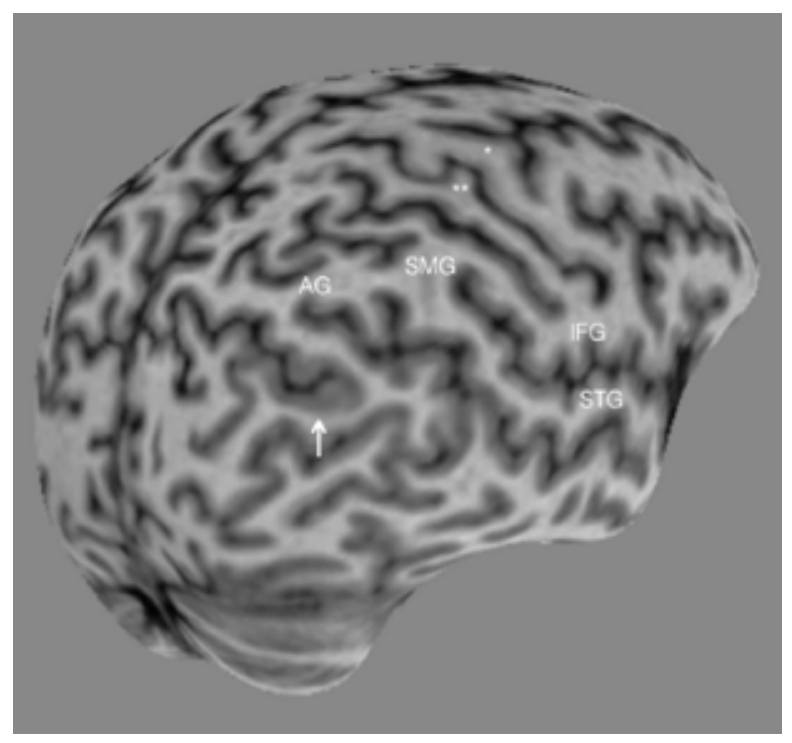

Fig. 1. Curvilinear reconstruction showing right parietal cortical thickness (arrow) and its correlation with adjacent gyrus. GA: Angular gyrus; SMG: Supramarginal gyrus; IFG: Inferior frontal gyrus; STG: Superior temporal gyrus; * precentral gyrus; ${ }^{* *}$ Postcentral gyrus.

In this context, MRI epilepsy protocols should include a 3D, T1-weighted volumetric acquisitions with isotropic voxel of 1 or $1.5 \mathrm{~mm}$ in order to reconstruct images in any plane (Figure 3), as well as, FLAIR 3D (Fluid Attenuation Inversion Recovery), T1-weighted IR (inversion recovery) and DIR 3D (Double Inversion Recovery) sequences should be added, mainly when cortical dysplasia is considered. For mesial temporal lobe epilepsy (MTLE), other sequences are also important: thin coronal MRI slices, perpendicular to the long axis of the hippocampus (Figure 2), T2-weighted, FLAIR and T1-weighted IR.

In addition to the technical aspects of MRI acquisition, the experience of the examiner and a clinical/encephalographic correlation are essential when searching for subtle epileptogenic lesions. ${ }^{[8,9]}$

\section{Most Frequent MRI Findings According to the Clinical Syndromes}

\section{Temporal Lobe Epilepsy (TLE)}

TLE is the most frequent form of focal epilepsy in adults. ${ }^{[10]}$ One third of patients are pharmaco-resistant. TLE is frequently associated with structural abnormalities, but other forms of non-lesional TLEs have been described, such as some forms of familial temporal lobe epilepsy (Figure 4). ${ }^{[11-13]}$ 
Table 1. Suggestion of MRI hippocampal protocol

\section{Coronal images perpendicular to the long axis of the hippocampus}

1) $\mathrm{T} 2 \mathrm{WI}$ multiecho (3- mm-thick, no gap, voxel size $=$ $0.89 \times 1 \times 3 \mathrm{~mm}, \mathrm{TR}=3300 \mathrm{~ms}, \mathrm{TE}=30 / 60 / 90 / 120 / 150$ $\mathrm{ms}$, matrix $=200 \times 180, \mathrm{FOV}=180 \times 180$, TSE factor $=5$; EPI factor $=5$, flip angle $=90^{\circ}$;

2) T1WI inversion recovery (3-mm-thick, no gap, voxel size $=0.75 \times 0.75 \times 3 \mathrm{~mm}, \mathrm{TR}=3550 \mathrm{~ms}, \mathrm{TE}=15 \mathrm{~ms}, \mathrm{Tl}=$ $400 \mathrm{~ms}$, matrix $=240 \times 229, \mathrm{FOV}=180 \times 180$, TSE factor $=$ 7),

3) FLAIR (fat-suppressed = spectral-attenuated inversion recovery, fat-suppressed power $=1$, four-mmthick, section gap $=1 \mathrm{~mm}$, voxel size $=0.89 \times 1.1 \times 2.4$ $\mathrm{mm}, \mathrm{TR}=12,000 \mathrm{~ms}, \mathrm{TE}=140 \mathrm{~ms}, \mathrm{Tl}=2850 \mathrm{~ms}$, matrix $=180 \times 440, \mathrm{FOV}=200 \times 200$ ).

\section{Axial images parallel to the long axis of the hippo-} campus

1) FLAIR (fat-suppressed = spectral-attenuated inversion recovery, fat-suppressed power $=1$, four-mmthick, section gap $=1 \mathrm{~mm}$, voxel size $=0.89 \times 1.1 \times 2.4$ $\mathrm{mm}, \mathrm{TR}=12000 \mathrm{~ms}, \mathrm{TE}=140 \mathrm{~ms}, \mathrm{TI}=2850 \mathrm{~ms}$, matrix $=224 \times 160, \mathrm{FOV}=200 \times 200$ ).

2) T1WI volume: isotropic voxels of $1 \mathrm{~mm}$, acquired in the sagittal plane (1-mm-thick, no gap, flip angle $=$ $8^{\circ}, \mathrm{TR}=7.0 \mathrm{~ms}, \mathrm{TE}=3.2 \mathrm{~ms}$, matrix $=240 \times 240, \mathrm{FOV}=$ 240x240).

3) T2WI volume: isotropic voxels of $1.5 \mathrm{~mm}$, acquired in the sagittal plane (no gap, $T R=1800 \mathrm{~ms}, \mathrm{TE}=340 \mathrm{~ms}$, matrix $=140 \times 140$, FOV $=230 \times 230$, TSE factor $=120$; flip angle $=90^{\circ} ;$ geometry-corrected).

4) DTI (Diffusion Tensor Imaging) - Spin echo single shot planar imaging, voxel size $=2 \times 2 \times 2 \mathrm{~mm}$, matrix $=$ $256 \times 256$, TE/TR 61/8500 ms, gradient directions $=32$.

\section{Sagittal images parallel to the long axis of hippocam- pus}

1) $\mathrm{T} 2 \mathrm{WI}$ 3D: no gap, FOV $=230 \times 230$, voxel size $=$ $1,5 \times 1,5 \times 1,5 \mathrm{~mm}, \mathrm{TR}=1800 \mathrm{~ms}$, TE shortest.

2) FLAIR $3 D$ (fat-suppressed = spectral-attenuated inversion recovery): FOV: $250 \times 250$, voxel size $=1,2 \times 1,2 \times 1,0$ $\mathrm{mm}, \mathrm{TR}=4800 \mathrm{~ms}$, TE shortest, $\mathrm{Tl}=1650 \mathrm{~ms}$.

\section{MTLE with Hippocampal Sclerosis (HS)}

In MTLE, electroencephalographic findings, clinical history and neuroimaging findings are important to define the diagnosis. Although there are others etiologies that cause ELT, HS is the most common pathological substrate. MTLE with
Table 2. Suggestion of MRI focal cortical dysplasia protocol

1) T1WI volume: isotropic voxels of $1 \mathrm{~mm}$, acquired in the sagittal plane $(1-\mathrm{mm}$-thick, no gap, flip angle $=$ $8^{\circ}, \mathrm{TR}=7.0 \mathrm{~ms}, \mathrm{TE}=3.2 \mathrm{~ms}$, matrix $=240 \times 240, \mathrm{FOV}=$ 240×240).

2) FLAIR 3D, acquired in the sagittal plane (fatsuppressed $=$ spectral-attenuated inversion recovery): FOV: $250 \times 250$, voxel size $=1,2 \times 1,2 \times 1,0 \mathrm{~mm}, \mathrm{TR}$ $=4800 \mathrm{~ms}$, TE shortest, $\mathrm{TI}=1650 \mathrm{~ms}$

3) FLAIR (fat-suppressed $=$ spectral-attenuated inversion recovery, fat-suppressed power $=1$, four-mmthick, section gap $=1 \mathrm{~mm}$, voxel size $=0.89 \times 1.1 \times 2.4$ $\mathrm{mm}, \mathrm{TR}=12000 \mathrm{~ms}, \mathrm{TE}=140 \mathrm{~ms}, \mathrm{Tl}=2850 \mathrm{~ms}$, matrix $=224 \times 160, \mathrm{FOV}=200 \times 200$ ).

4) $\mathrm{T} 2 \mathrm{WI} 3 \mathrm{D}$, acquired in the sagittal plane: no gap, $\mathrm{FOV}=$ $230 \times 230$, voxel size $=1,5 \times 1,5 \times 1,5 \mathrm{~mm}, \mathrm{TR}=1800 \mathrm{~ms}$, TE shortest.

5) T1WI inversion recovery (3-mm-thick, no gap, voxel size $=0.75 \times 0.75 \times 3 \mathrm{~mm}, \mathrm{TR}=3550 \mathrm{~ms}, \mathrm{TE}=15 \mathrm{~ms}, \mathrm{TI}=$ $400 \mathrm{~ms}$, matrix $=240 \times 229, \mathrm{FOV}=180 \times 180$, TSE factor $=7$ ),

6) DIR (double inversion recovery), acquired in th axial plane perpendicular to the long axis of the hippocampus: voxel size $=1.2 \times 1.2 \times 0.6 \mathrm{~mm}, \mathrm{TR}=5500 \mathrm{~ms}$, TE shortest, TI $2550 \mathrm{~ms}$.

7) DTI (Diffusion Tensor Imaging) - Spin echo single shot planar imaging, voxel size $=2 \times 2 \times 2 \mathrm{~mm}$, matrix $=$ $256 \times 256$, TE/TR $61 / 8500 \mathrm{~ms}$, gradient directions $=32$.

HS is often associated with a precipitating injury such as complex febrile seizures, birth trauma, meningitis or head injury that happens in early life. ${ }^{[14]} \mathrm{A}$ latent period of several years may precede dyscognitive seizures (previously known as complex partial seizures). ${ }^{[15]}$

The MRI findings often show volumetric reduction of hippocampal formation (atrophy), increased signal intensity in T2-weighted sequences, loss of normal hippocampal architecture with loss of hippocampal head digitation (Figure 5) better identified in thin coronal MRI slices, perpendicular to the axis of the hippocampus. ${ }^{[16]}$

Secondary MRI findings of HS include: atrophy of structures of the limbic system, such as amygdala, ipsilateral mammillary body, entorhinal cortex, ipsilateral fornix, posterior thalamus, cingulate gyrus and contralateral cerebellum. ${ }^{[17,18]}$ Atrophy-signal alterations of the contralateral hippo- 

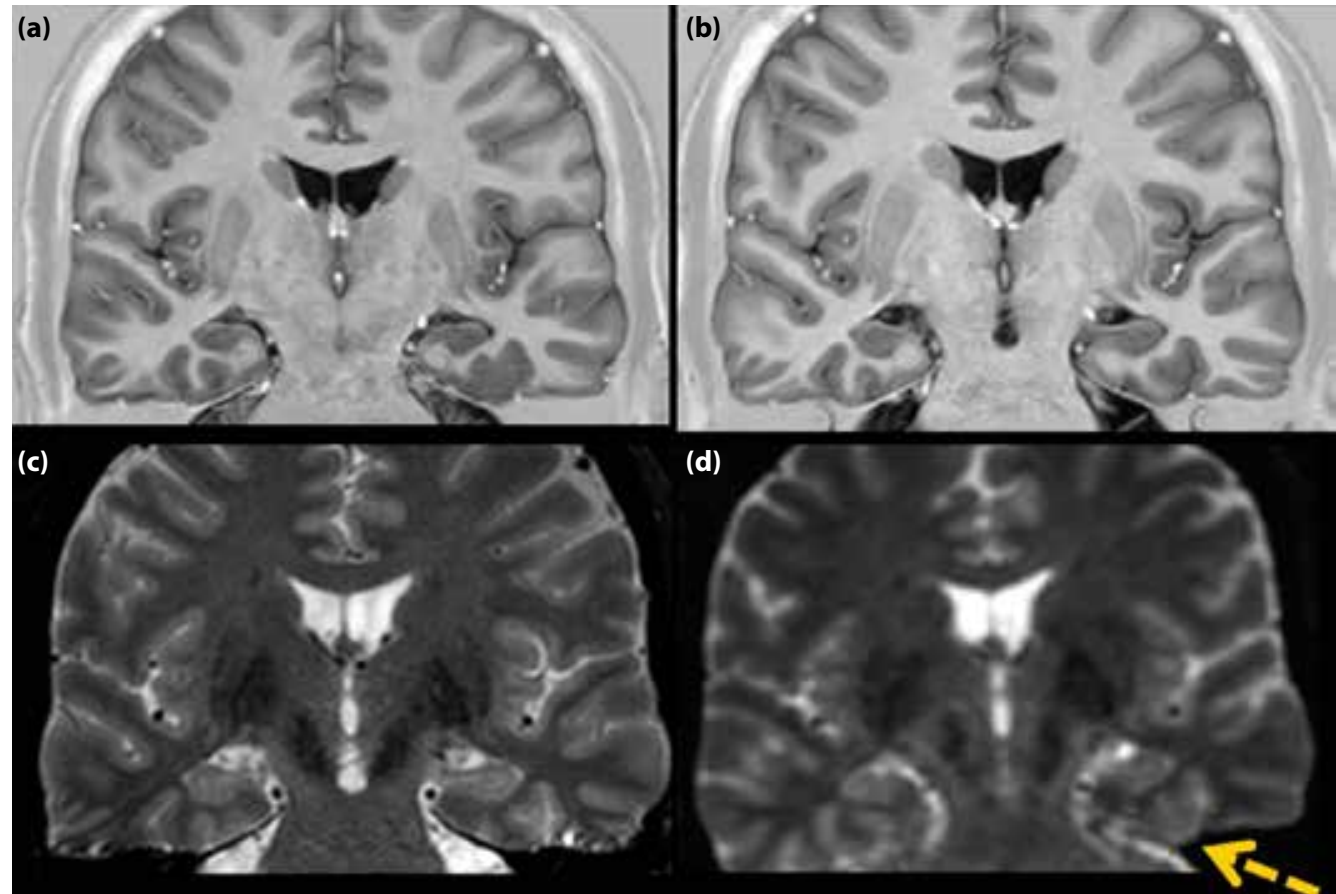

Fig. 2. (a-d) T1 IR and T2WI MRI sequences showing subtle FCD in the left collateral sulcus.

campus and dilation of the ipsilateral temporal horn of the lateral ventricle can also be present. ${ }^{[19]}$

Although about 10 - $20 \%$ of patients have symmetrical bilateral HS, the comparison between both hippocampi is also an important tool to detect asymmetries (Margerison and Corsellis, 1966) bearing in mind, that sometimes, mild hippocampal atrophy with or without increased T2/FLAIR signal may be found in MRI scans in older patients related to aging.

\section{MTLE with Normal MRI}

Some patients with MTLE may have an MRI read as normal.

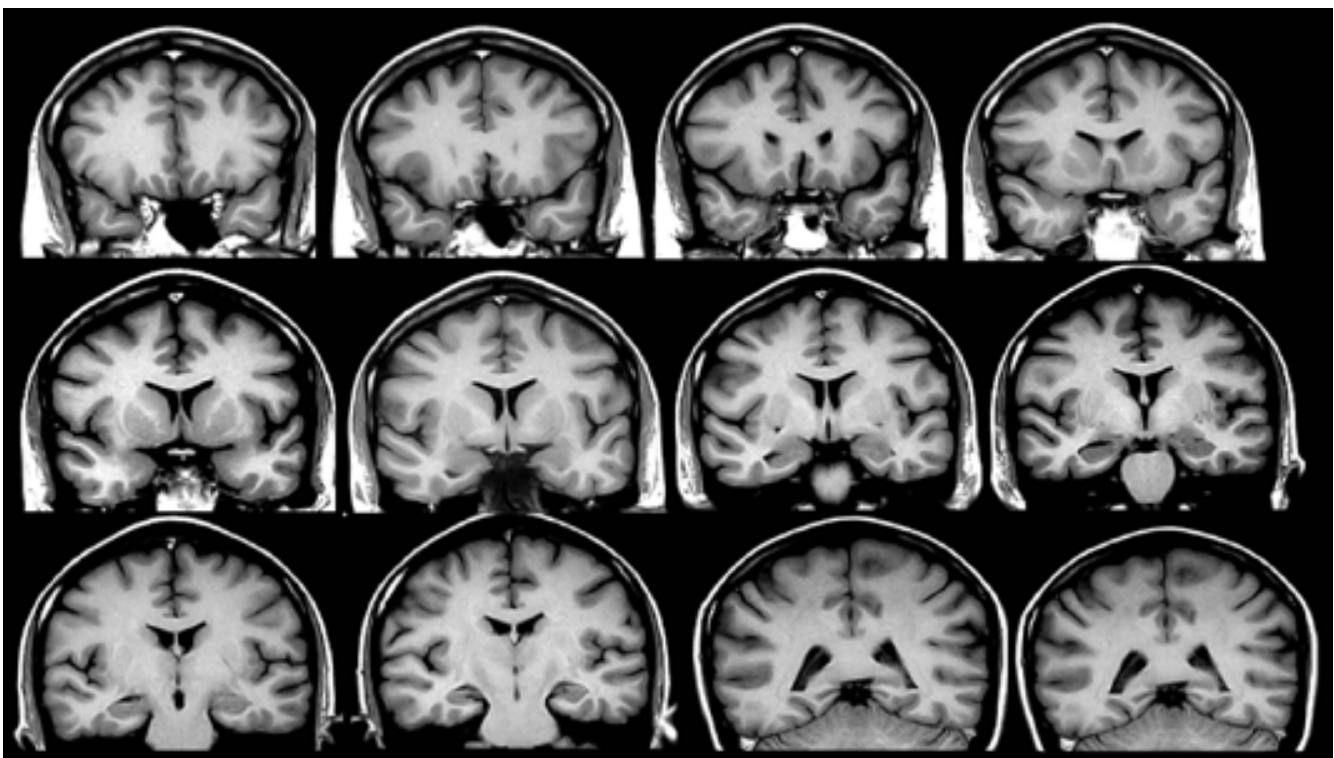

Fig. 3. Normal 3D T1 WI MRI in coronal slices volumetric acquisitions. 


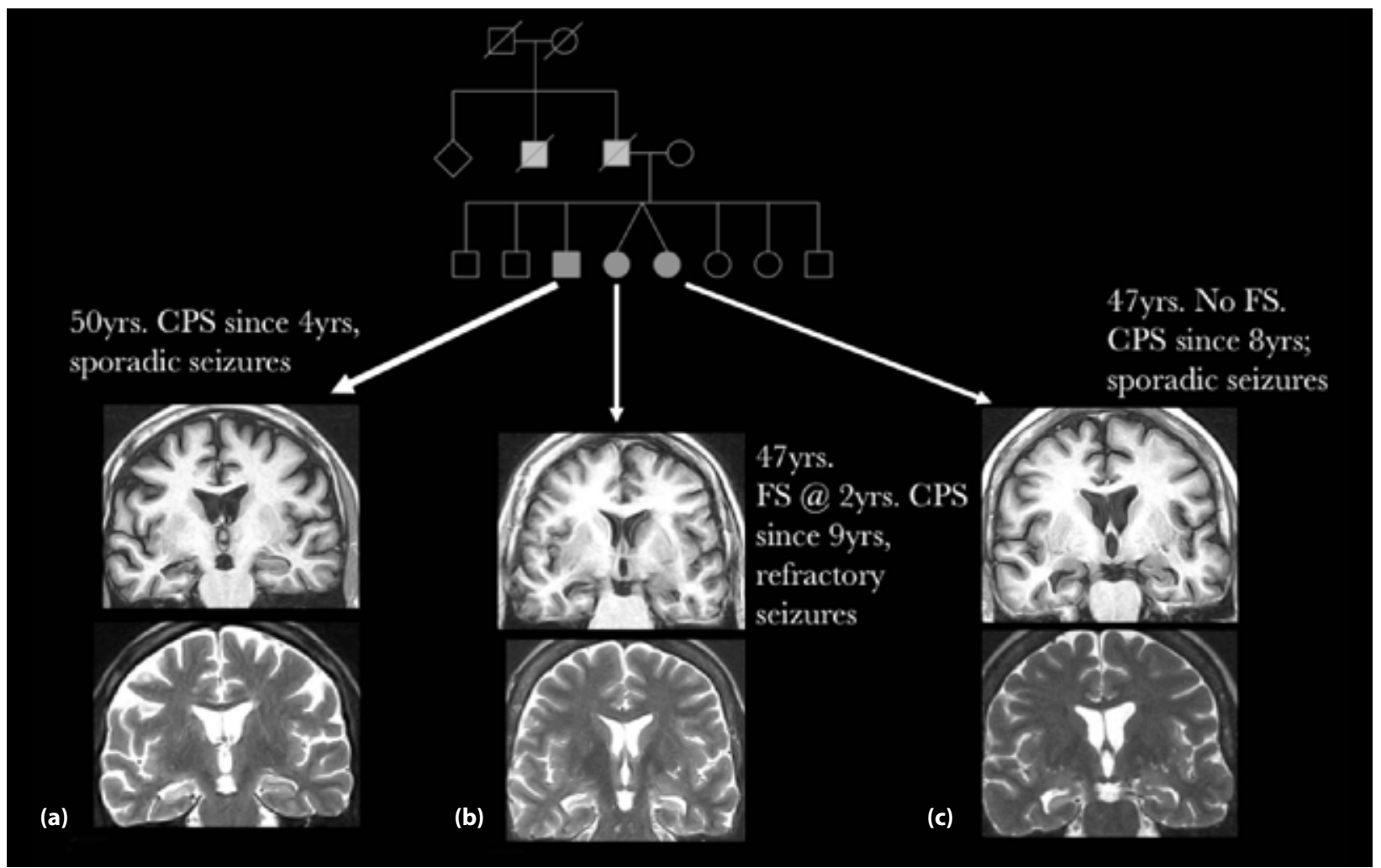

Fig. 4. $T 1$ and $T 2 M R I$ sequences in coronal slices showing familiar MTLE with right $H S(\mathbf{a}, \mathbf{c})$ and bilateral HS (b).

${ }^{[20,21]}$ In these cases, advanced techniques of imaging including magnetic resonance spectroscopy (MRS), interictal FDGPET, ictal SPECT (Figure 9), quantitative analysis of hippocampus formation such as volumetry and relaxometry, ${ }^{[22-25]}$ can be useful tools for diagnostic and lateralization of seizure onset (Figure 6).

In refractory epilepsies, when a focal lesion is found, surgery is the best treatment. In these cases, appropriate MRI protocols and expertise in MRI of epilepsy are required. On the other hand, when no lesion is found, the area of resection has to be defined by other tools (e.g. EEG, PET, SPECT); however, a less optimal surgical outcome may be expected. ${ }^{[15]}$

Although the HS is the most common structural abnormality found in TLE, there are many other causes that may lead to TLE such as tumors (Figure 7), gliosis, vascular malformations, congenital cysts and a wide variety of malformation of cortical development, which may lead to similar clinical findings to those of MTLE due to HS (Figure 12). ${ }^{[26]}$

\section{Extra-Temporal Lobe Epilepsy}

Focal lesions outside the temporal lobe are frequently resistant to clinical treatment, with up to $25-30 \%$ of patients
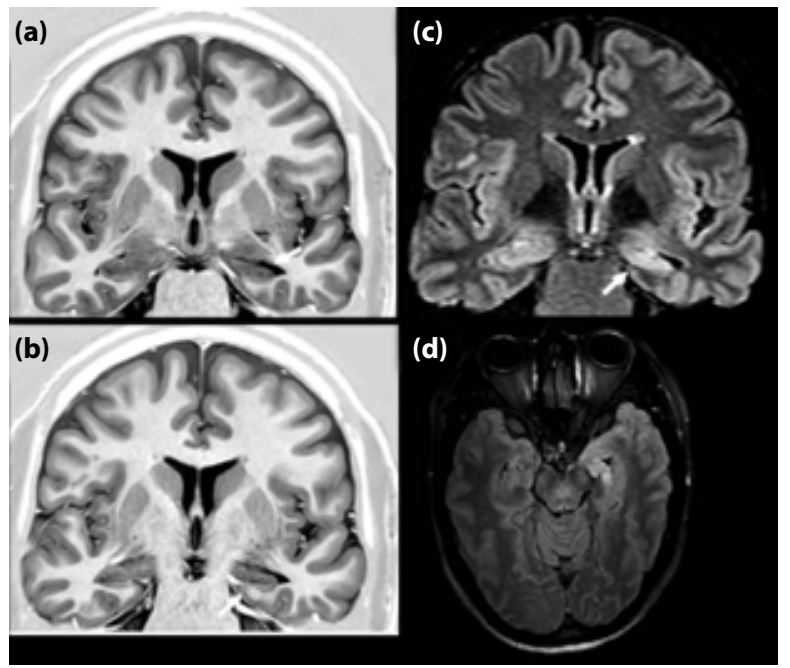

Fig. 5. (a, b) T1 IR and (c, d) FLAIR MRI sequences showing left HS, characterized by volumetric reduction of hippocampus, increased signal intensity and loss normal architecture. 


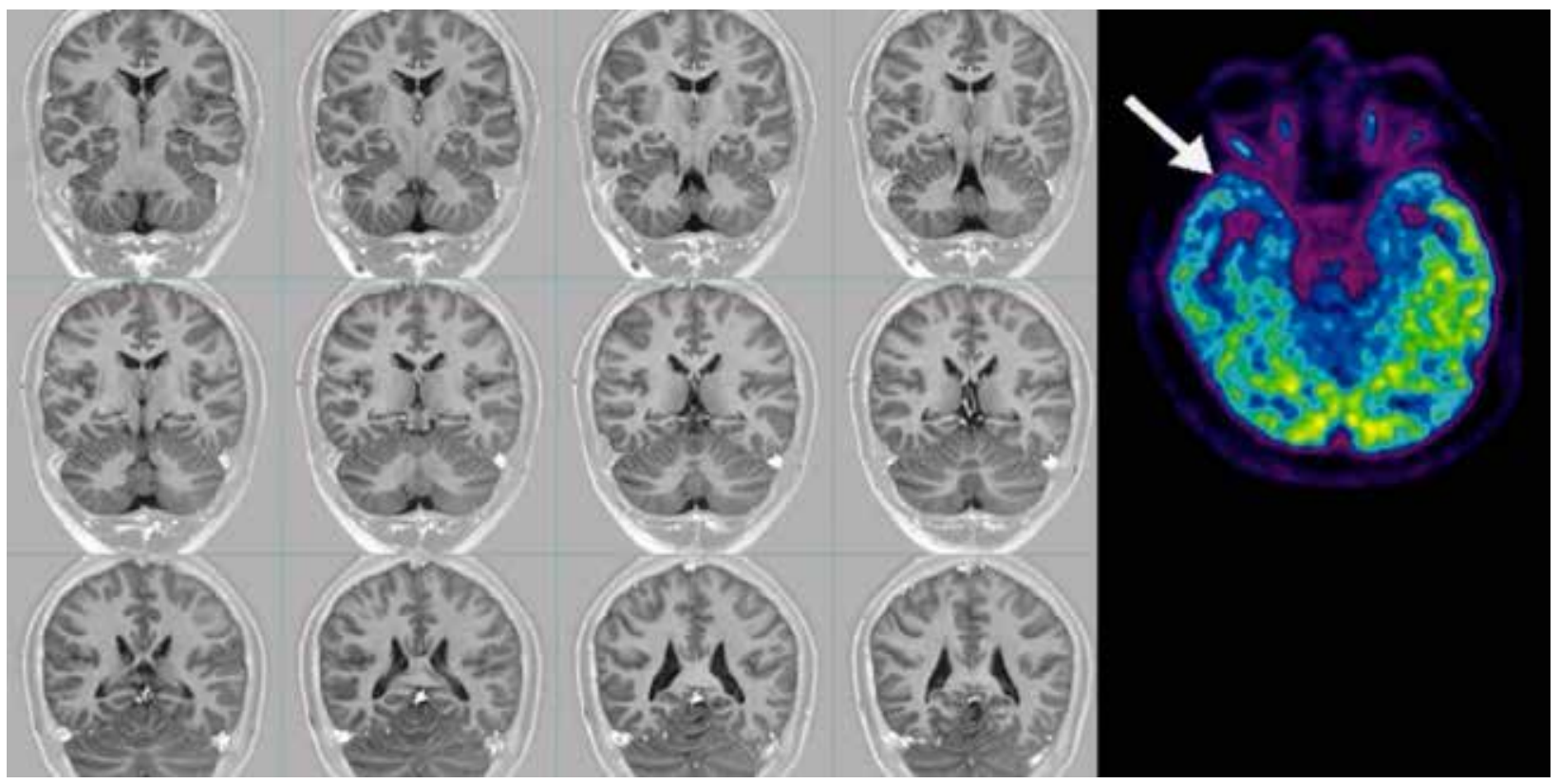

Fig. 6. T1 IR MRI sequence with normal findings and FDG-PET showing hypometabolism in the temporal lobe.

being refractory to AEDs. Clinical presentation depends on the exact location of the abnormality. Defining the focal epileptogenic zone is of paramount importance, since good surgical outcome depends on complete resection of the lesion displayed on MRI and the surrounding "MRI-invisible" epileptogenic tissue. ${ }^{[27-29]}$

In extra-temporal lesions, the MRI investigation has its own features. MRI may be unremarkable even in malformations of cortical development. In these cases, multimodal techniques of imaging can be useful for localizing suspected le- sions. Among the multimodal imaging, the interictal FDGPET, ictal SPECT, ictal/interictal subtraction of SPECT scans, PET/MRI co-registration, multiplanar reconstruction and curvilinear reformatting represent noninvasive methods to evaluate patients with focal seizures (Figure 8). ${ }^{[30-32]}$

The most common lesions causing neocortical epilepsies are: low grade tumors, malformations of cortical development, posttraumatic and postischemic lesions, inflammatory infectious scars, cavernous angioma and arteriovenous malformations.

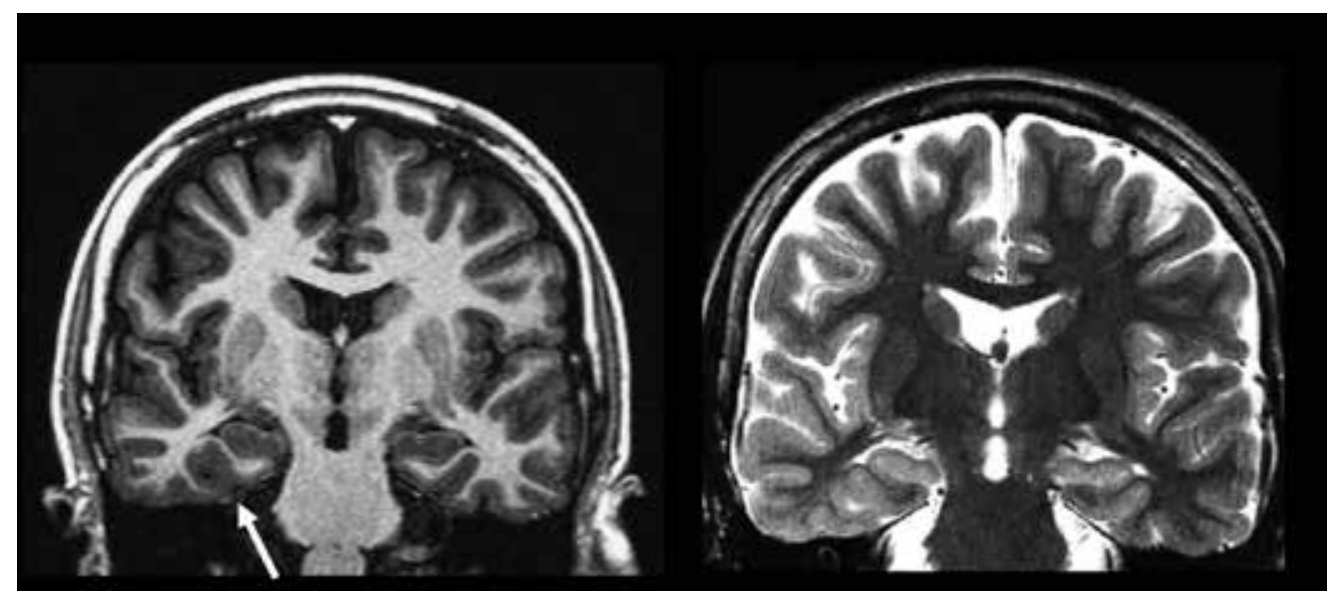

Fig. 7. Patient with MTLE and previous MRI reported as normal showing right temporal lobe lesion that was low grade ganglioglioma. 


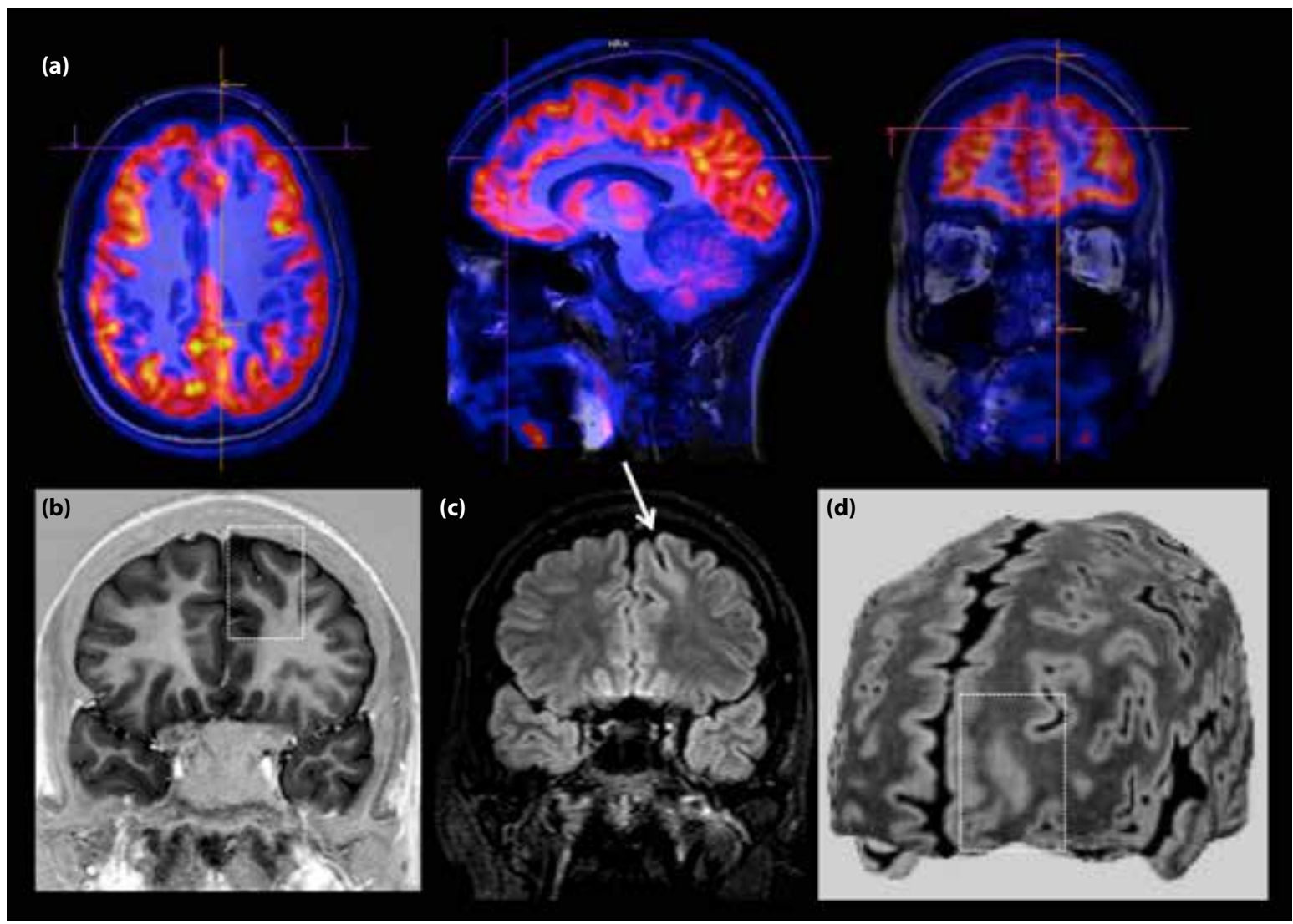

Fig. 8. Deep bottom sulcus dysplasia. (a) FDG-PET showing left frontal lobe hypometabolism. (b, c) T1WI and FLAIR MRI sequences coronal slices show cortical thickness in the left superior frontal sulcus with hyperintensity of white matter. (d) Curvilinear reconstruction shows similar findings and extension of these lesions, allowing surgery planning.

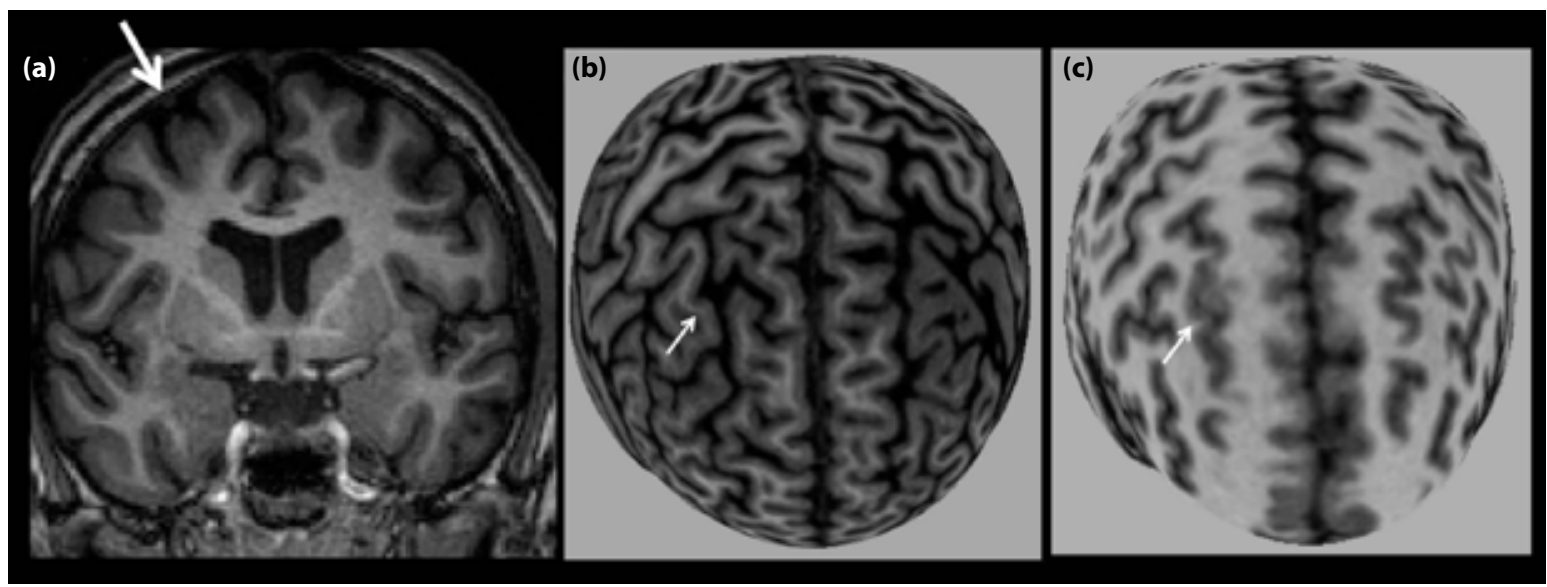

Fig. 9. T1WI coronal MRI sequence (a) and curvilinear reconstruction (b) showing changes in the pattern of brain sulci and gyri in the superior and middle frontal gyrus. Deeper curvilinear reconstruction (c) shows better the FCD, characterized by blurring of white and grey matter transition and cortical thickness. 


\section{Cortical Developmental Malformations}

\section{Focal Cortical Dysplasia}

Focal cortical dysplasia (FCD) is an abnormality of cortical development. ${ }^{[33]}$ This term designates a spectrum of histological abnormalities in the structure of the laminar cortex, with various degrees of architectural and cytopathological abnormalities, ${ }^{[34,35]}$ including dysmorphic neurons and balloon cells. FCD is the most common form of developmental disorder in patients with pharmacologically intractable focal epilepsies referred to pre-surgical evaluation. ${ }^{[36]}$

The current classification subdivided FCD into three types: Type I (no dysmorphic neurons or balloon cells), Type II (dysmorphic neurons with or without balloon cells) and Type III (FCD associated with another lesion). ${ }^{[37]}$

The advent of MRI was essential for brain assessment and new MRI technology allows detection of smaller and subtler lesions. FCD is characterized on MRI by variable degrees of cortical thickening, blurring of the gray-white matter interface and hyperintense T2/FLAIR signal within the dysplastic lesion relative to normal cortex, and sometimes in the adjacent subcortical region. ${ }^{[38]}$ Sometimes, changes in the pattern of brain sulci and gyri may be the main abnormalities, indicating the localization of seizure onset. Sometimes these findings can be associated with a cleft-dimple complex, defined as a cerebral spine fluid (CSF) space and a cortical dimple adjacent to a region of cortical digenesis (Figures 9, 10). ${ }^{[39]}$ To validate these MRI findings, correlation with clinical and electroencephalographic data is necessary.

Another important MRI subcortical white matter abnormality is the "transmantle sign", better viewed in $3 \mathrm{~T} \mathrm{MRI,}{ }^{[40,41]}$ characterized by a line of hyperintense signal on $\mathrm{T} 2 \mathrm{WI}$ and FLAIR and hypointense in T1WI sequences, crossing through the entire cerebral mantle, from the ventricular surface to the cerebral cortex. It is most frequently associated

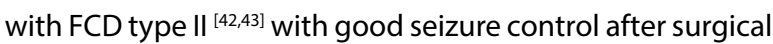
treatment (Figure 11). ${ }^{[44]}$

Studies showed that about $42 \%$ of patients with MRI-negative had $F C D,{ }^{[45]}$ suggesting that only routine MRI imaging may be not enough for evaluation of pharmaco-resistant epilepsy patients. Thereby, multimodal noninvasive techniques, including functional and quantitative MRI techniques are a promising option when no lesion is found.

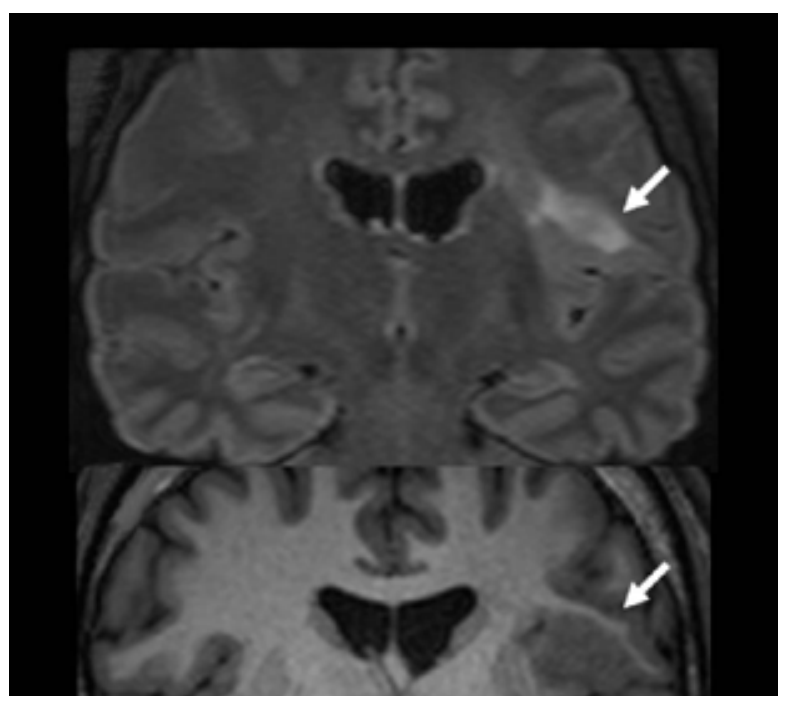

Fig. 10. T1WI axial MRI sequence showing cleft dimple-complex in the right frontal lobe.

Depending on the FCD type, MRI characteristics differ. As discussed before, MRI findings of FCD type II are usually more perceptible and clearer. The other types may show subtle findings (eg. changes in the pattern of brain sulci and gyri, deep sulci), that may indicate the location of the epileptogenic lesion together with clinical-EEG correlation.

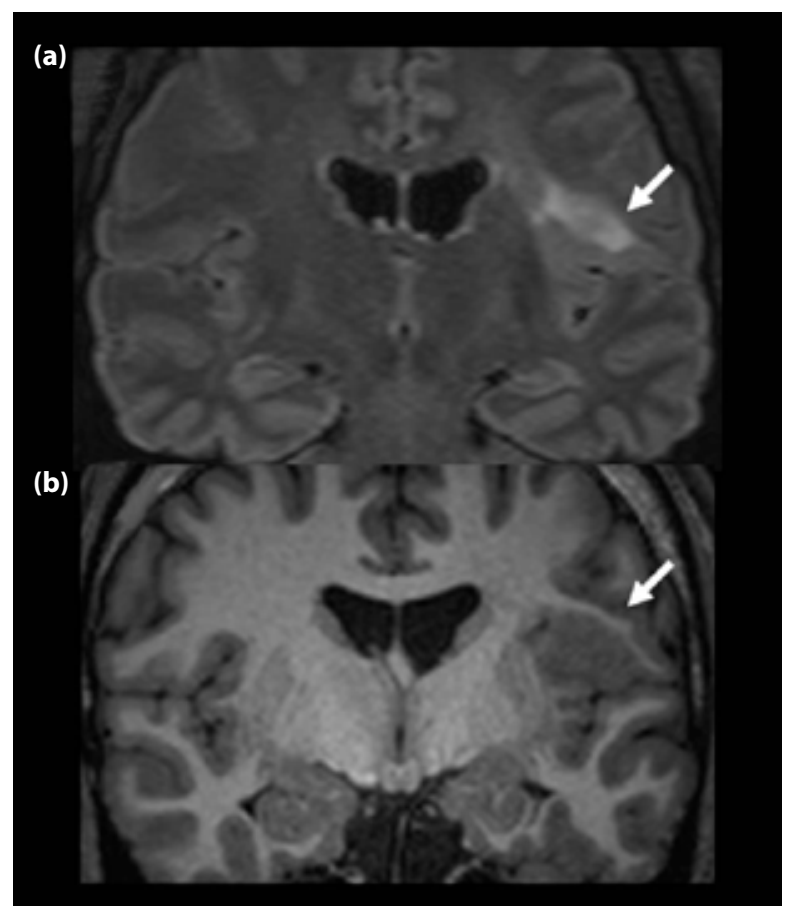

Fig. 11. FLAIR (a) and $T 1$ (b) MRI coronal slices showing left fronto-insular FCD with transmantle sign (arrow). 

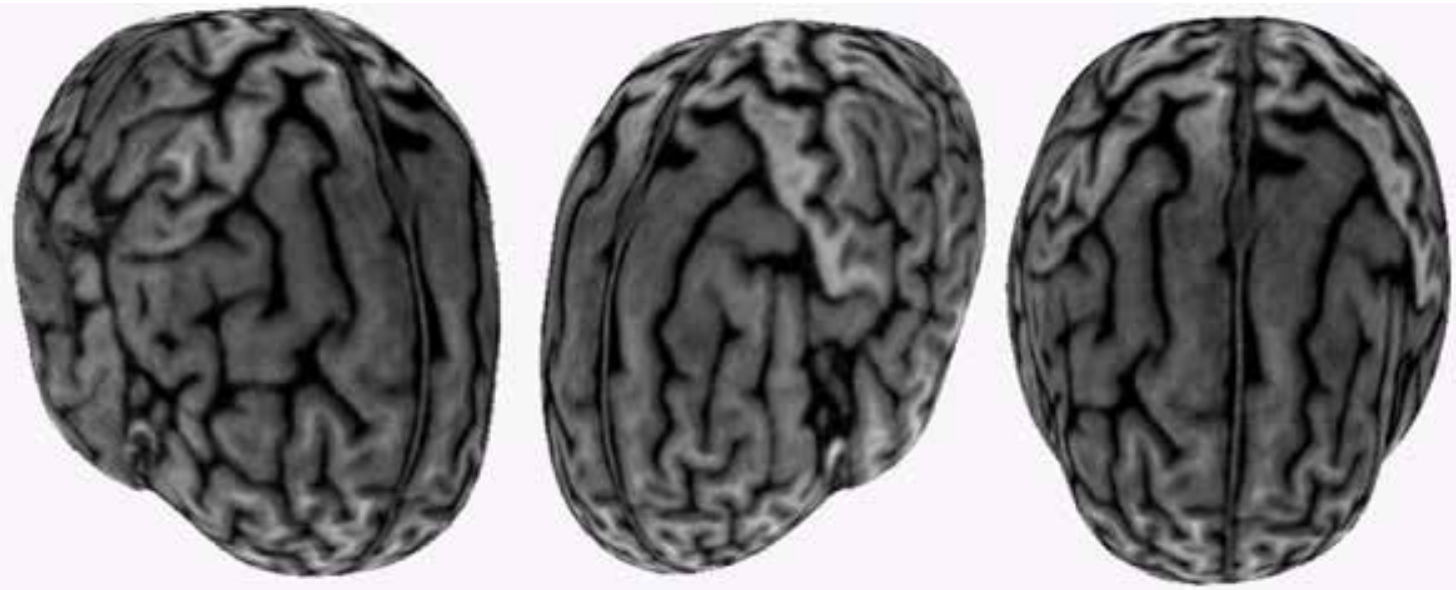

Fig. 12. Curvilinear reconstruction showing pachygiria features, characterized by simplified patterns of gyri and shallow sulci, assisting the structural imaging and providing good anatomical perspective.

Sometimes, FCD is localized at the bottom of a deep sulCus, $^{[46,47]}$ requiring more attention when reviewing MRI studies. Surgery is a good treatment option with excellent outcome when complete resection is achieved. ${ }^{[48]}$

\section{Polymicrogyria}

Polymicrogyria is one of the most common malformations of cortical development (MCD), characterized by excessive small and prominent convolutions separated by shallow sulci. It appears to be caused of variety mechanisms and often is associated with others malformative lesions such as cerebellar hypoplasia, callosum agenesis, periventricular nodular heterotopia, among others. ${ }^{[4]}$ Polymicrogyria is not always associated with epilepsy, and in those patients with epilepsies the seizures are often well controlled with medication.

Since the advent of MRI, this type of MCD has been ever more recognized. Additional reconstruction and curvilinear

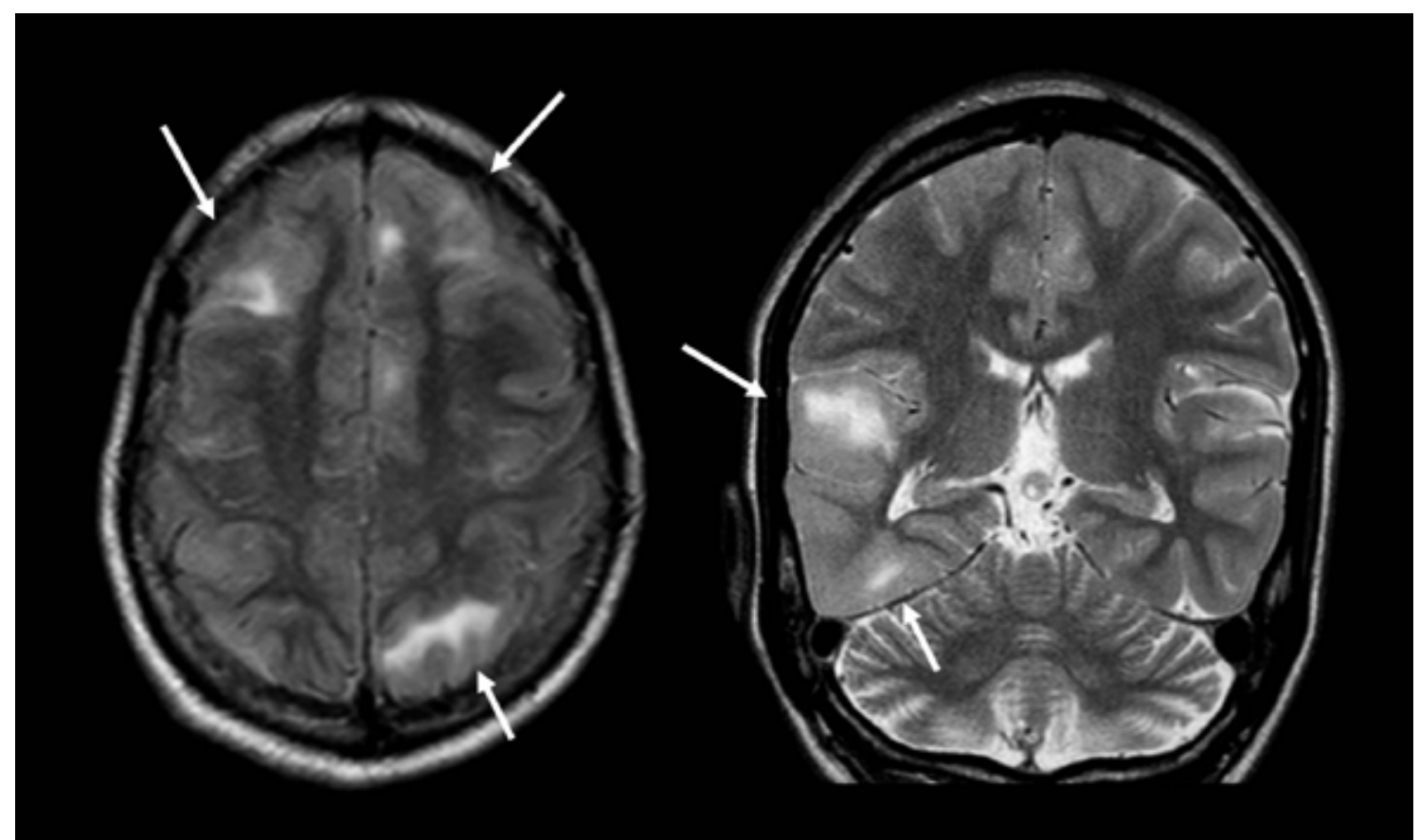

Fig. 13. FLAIR axial and coronal T2-W MRI sequences showing cortical tubers (arrows). 
reformatting can better show the extent and characteristics of the lesion. ${ }^{[50]}$

Another cortical developmental malformation that is always associated with polymicrogyria is schizencephaly, which is characterized by a cleft that connects cortical surface with ventricular lumen.

\section{Gray Matter Heterotopia (GMH)}

During normal brain development, in early gestation, the neurons start their migration outward, forming the functional hexalaminar cortex. If this process is disrupted, the neurons assume an abnormal position. These ectopic neurons may stop in any area between the subependimal region and the cerebral cortex.

These malformations can be divided into four subcategories:

1. Abnormalities of the neuroependima that occurs in the begining of migration, mainly comprising periventricular nodular heterotopia (PNH);

2. Generalized abnormalities of transmantle migration such as the lissencephalies;

3. Localized abnormalities of transmantle migration including subcortical band heterotopia (SBH);

4. Abnormalities due to abnormal terminal migration comprising cobblestone malformations. ${ }^{[51]}$

Although the etiology of GMH is not yet fully elucidated, genetics may play an important role. Patients often present with pharmaco-resistant epilepsy, in addition to focal neurologic deficits. ${ }^{[52]}$

PNH is the most common GMH. It is usually located in close proximity to the ventricular wall and appears in MRI as round or oval nodules, isointense to the normal gray matter, with no contrast enhancement, projecting into the ventricular lumen or lying on the periventricular white matter. ${ }^{[53]}$

Lissencephaly has several subtypes depending on the underlying genetic abnormality. It results from the arrest of the migration process. The classic type shows smooth brain surface with agyria and cortex thickening.

In SBH (also known as double cortex) extensive plates of heterotopic gray matter are located beneath the cortex, extending from the ventricular surface outward into the white matter without continuity with cerebral cortex. Most patients are female and it rarely affects males. Other patterns of $\mathrm{SBH}$ have been described, including pachygyria-SBH pattern, found in males. In MRI the heterotopic bands are isointense to the cortical gray matter on all MRI sequences with variable extension and thickness.

Curvilinear reconstruction is useful to identify cortical malformations. It reveals the extension of lesions in a clearer matter (Figure 12).

\section{Tuberous Sclerosis}

Tuberous Sclerosis (TS) is a phakomatosis with dysplasias and hamartomas affecting the brain. It may be sporadic or hereditary with an autosomal dominant pattern of inheritance and often causes pharmaco-resistant seizures that start as infantile spasms in the first months of life. MRI features includes cortical tubers that may be indistinguishable from FCD type II, subependymal calcified nodules and subependymal giant cell astrocytoma (Figure 13). ${ }^{[54]}$

\section{LEATs - Long Term Epilepsy Associated Tumors}

The long-term epilepsy associated tumors (LEATs) ${ }^{[55]}$ are those lesion identified in about $20-30 \%$ of patients who have been investigated and treated for drug resistant seizure episodes for two years or longer. These types of tumors may encompass gangliogliomas, dysembryoblastic neuroepitelial tumors, pleomorphic astrocytomas, diffuse astrocytomas, oligodendrogliomas and a few anaplastic tumors. They can occur in any part of brain, but it preferentially affects the temporal lobe region. These tumors usually present slow growth, and the main clinical feature is epilepsy.

MRI typical features are characterized by cystic alterations with or without calcification. Mural nodule can be enhanced after gadolinium injection. However, other MRI findings are associated with these tumors depending on the histological type. ${ }^{[56,57]}$

\section{Conclusion}

In the setting of clear cut abnormalities, standard MRI protocols may be sufficient. However, when standard MRI is considered normal, appropriate MRI epilepsy protocols are essential in the assessment epileptogenic lesions. Subtle MRI finding are only valued when considered together with 
clinical semiology, electroencephalographic data and other imaging techniques.

\section{References}

1. Scheffer IE, Berkovic SF, Capovilla G, Connolly MB, Guilhoto L, Hirsch E, et al. The Organization of the Epilepsies: Report of the ILAE Commission on Classification and Terminology. ILAE website 2014.

2. Banerjee PN, Filippi $D$, Allen Hauser W. The descriptive epidemiology of epilepsy-a review. Epilepsy Res 2009;85(1):31-45.

3. Mueller SG, Bateman LM, Laxer KD. Evidence for brainstem network disruption in temporal lobe epilepsy and sudden unexplained death in epilepsy. Neuroimage Clin 2014;5:208-16.

4. Kwan P, Schachter SC, Brodie MJ. Drug-resistant epilepsy. N Engl J Med 2011;365(10):919-26.

5. Mishra AM, Bai H, Gribizis A, Blumenfeld H. Neuroimaging biomarkers of epileptogenesis. Neurosci Lett 2011;497(3):194-204.

6. Hopkins A, Garman A, Clarke C. The first seizure in adult life. Value of clinical features, electroencephalography, and computerised tomographic scanning in prediction of seizure recurrence. Lancet 1988;1(8588):721-6.

7. Randomized clinical trial on the efficacy of antiepileptic drugs in reducing the risk of relapse after a first unprovoked tonicclonic seizure. First Seizure Trial Group (FIR.S.T. Group) Neurology 1993;43(3 Pt 1):478-83.

8. Horst U. MRI in Epilepsy. Springer 2013.

9. Cendes F. Neuroimaging in investigation of patients with epilepsy. Continuum (Minneap Minn) 2013;19:623-42.

10. Hauser WA, Annegers JF, Rocca WA. Descriptive epidemiology of epilepsy - contributions of population-based studies from Rochester, Minnesota. Mayo Clin Proc 1996;71:576-86.

11. Vadlamudi L, Scheffer IE, Berkovic SF. Genetics of temporal lobe epilepsy. Journal of Neurology, Neurosurgery \& Psychiatry 2003;74:1359-61.

12. Crompton DE, Scheffer IE, Taylor I, Cook MJ, McKelvie PA, Vears DF, et al. Familial mesial temporal lobe epilepsy: a benign epilepsy syndrome showing complex inheritance. Brain 2010;133(11):3221-31.

13. Morita ME, Yasuda CL, Betting LE, Pacagnella D, Conz L, Barbosa $\mathrm{PH}$, et al. MRI and EEG as long-term seizure outcome predictors in familial mesial temporal lobe epilepsy. Neurology 2012;79(24):2349-54.

14. Blümcke I, Thom M, Wiestler OD. Ammon's horn sclerosis: a maldevelopmental disorder associated with temporal lobe epilepsy. Brain Pathol 2002;12(2):199-211.

15. Cendes F, Kahane P, Brodie MJ, Andermann F. The mesio-temporal lobe epilepsy syndrome. Epileptic syndromes in infancy, childhood and adolescence, 5th ed. Eastleigh: John Libbey Eurotext Ltd; 2012.

16. Cendes F, Sakamoto AC, Spreafico R, Bingaman W, Becker AJ. Epilepsies associated with hippocampal sclerosis. Acta Neuropathol 2014;128(1):21-37.

17. Chan S, Erickson JK, Yoon SS. Limbic system abnormalities associated with mesial temporal sclerosis: a model of chronic cerebral changes due to seizures. Radiographics 1997;17(5):1095110.

18. Urbach H, Siebenhaar G, Koenig R, von Oertzen J, Scorzin J, Kurthen $\mathrm{M}$, et al. Limbic system abnormalities associated with Ammon's horn sclerosis do not alter seizure outcome after amygdalohippocampectomy. Epilepsia 2005;46(4):549-55.

19. Margerison JH, Corsellis JA. Epilepsy and the temporal lobes. A clinical, electroencephalographic and neuropathological study of the brain in epilepsy, with particular reference to the temporal lobes. Brain 1966;89(3):499-530.

20. Engel J Jr. Introduction to temporal lobe epilepsy. Epilepsy Res 1996;26(1):141-50.

21. Van Paesschen W, Connelly A, King MD, Jackson GD, Duncan JS. The spectrum of hippocampal sclerosis: a quantitative magnetic resonance imaging study. Ann Neurol 1997;41(1):41-51.

22. Coan AC, Kubota B, Bergo FP, Campos BM, Cendes F. 3T MRI quantification of hippocampal volume and signal in mesial temporal lobe epilepsy improves detection of hippocampal sclerosis. AJNR Am J Neuroradiol 2014;35(1):77-83.

23. Carne RP, O'Brien TJ, Kilpatrick CJ, MacGregor LR, Hicks RJ, Murphy MA, et al. MRI-negative PET-positive temporal lobe epilepsy: a distinct surgically remediable syndrome. Brain 2004;127(Pt 10):2276-85.

24. Coan AC, Bonilha L, Morgan PS, et al. T2-weighted and T2 relaxometry images in patients with medial temporal lobe epilepsy. J Neuroimaging 2006;16(3):260-5.

25. Cohen-Gadol AA, Bradley CC, Williamson A, Kim JH, Westerveld $M$, Duckrow RB, et al. Normal magnetic resonance imaging and medial temporal lobe epilepsy: the clinical syndrome of paradoxical temporal lobe epilepsy. J Neurosurg 2005;102(5):902-9.

26. Taylor DC, Falconer MA, Bruton CJ, Corsellis JA. Focal dysplasia of the cerebral cortex in epilepsy. J Neurol Neurosurg Psychiatry 1971;34(4):369-87.

27. Awad IA, Rosenfeld J, Ahl J, Hahn JF, Lüders H. Intractable epilepsy and structural lesions of the brain: mapping, resection strategies, and seizure outcome. Epilepsia 1991;32(2):179-86.

28. Fried I, Cascino GD. Lesional surgery. In: Engel J Jr, ed. Surgical treatment of the epilepsies. 2nd ed. New York: Raven Press 1993:501-9.

29. Lee SK, Lee SY, Kim KK, Hong KS, Lee DS, Chung CK. Surgical outcome and prognostic factors of cryptogenic neocortical 
epilepsy. Ann Neurol 2005;58(4):525-32.

30. Hong SJ, Kim H, Schrader D, Bernasconi N, Bernhardt BC, Bernasconi A. Automated detection of cortical dysplasia type II in MRI-negative epilepsy. Neurology 2014;83(1):48-55.

31. Salamon N, Kung J, Shaw SJ, Koo J, Koh S, Wu JY, et al. FDG-PET/ MRI coregistration improves detection of cortical dysplasia in patients with epilepsy. Neurology 2008;71(20):1594-601.

32. Perissinotti A, Setoain $X$, Aparicio J, Rubí S, Fuster BM, Donaire $A$, et al. Clinical Role of Subtraction Ictal SPECT Coregistered to MR Imaging and (18)F-FDG PET in Pediatric Epilepsy. J Nucl Med 2014;55(7):1099-105.

33. Barkovich AJ, Guerrini R, Kuzniecky Rl, Jackson GD, Dobyns WB. A developmental and genetic classification for malformations of cortical development: update 2012. Brain 2012;135(Pt 5):1348-69.

34. Taylor DC, Falconer MA, Bruton CJ, Corsellis JA. Focal dysplasia of the cerebral cortex in epilepsy. J Neurol Neurosurg Psychiatry 1971;34(4):369-87.

35. Palmini A, Najm I, Avanzini G, Babb T, Guerrini R, FoldvarySchaefer $\mathrm{N}$, et al. Terminology and classification of the cortical dysplasias. Neurology 2004;62(6 Suppl 3):2-8.

36. Sisodiya SM. Surgery for malformations of cortical development causing epilepsy. Brain 2000;123 ( Pt 6):1075-91.

37. Blümcke I, Thom M, Aronica E, Armstrong DD, Vinters HV, Palmini $A$, et al. The clinicopathologic spectrum of focal cortical dysplasias: a consensus classification proposed by an ad hoc Task Force of the ILAE Diagnostic Methods Commission. Epilepsia 2011;52(1):158-74.

38. Barkovich AJ, Kuzniecky RI. Neuroimaging of focal malformations of cortical development. J Clin Neurophysiol 1996;13(6):481-94.

39. Bronen RA, Spencer DD, Fulbright RK. Cerebrospinal fluid cleft with cortical dimple: MR imaging marker for focal cortical dysgenesis. Radiology 2000;214(3):657-63.

40. Barkovich AJ, Kuzniecky RI, Bollen AW, Grant PE. Focal transmantle dysplasia: a specific malformation of cortical development. Neurology 1997;49(4):1148-52.

41. Mellerio C, Labeyrie MA, Chassoux F, Roca P, Alami O, Plat M, et al. 3T MRI improves the detection of transmantle sign in type 2 focal cortical dysplasia. Epilepsia 2014;55(1):117-22.

42. Krsek P, Maton B, Korman B, Pacheco-Jacome E, Jayakar P, Dunoyer $C$, et al. Different features of histopathological subtypes of pediatric focal cortical dysplasia. Ann Neurol 2008;63(6):75869.

43. Wagner J, Urbach $H$, Niehusmann $P$, von Lehe $M$, Elger $C E$, Wellmer J. Focal cortical dysplasia type Ilb: completeness of cortical, not subcortical, resection is necessary for seizure freedom. Epilepsia 2011;52(8):1418-24.
44. Wang DD, Deans AE, Barkovich AJ, Tihan T, Barbaro NM, Garcia $\mathrm{PA}$, et al. Transmantle sign in focal cortical dysplasia: a unique radiological entity with excellent prognosis for seizure control. J Neurosurg 2013;118(2):337-44.

45. Chapman K, Wyllie E, Najm I, Ruggieri P, Bingaman W, Lüders $J$, et al. Seizure outcome after epilepsy surgery in patients with normal preoperative MRI. J Neurol Neurosurg Psychiatry 2005;76(5):710-3.

46. Besson P, Andermann F, Dubeau F, Bernasconi A. Small focal cortical dysplasia lesions are located at the bottom of a deep sulcus. Brain 2008;131(Pt 12):3246-55.

47. Mellerio $C$, Roca $P$, Chassoux F, Danière F, Cachia A, Lion S, et al. The power button sign: a newly described central sulcal pattern on surface rendering MR images of type 2 focal cortical dysplasia. Radiology 2015;274(2):500-7.

48. See SJ, Jehi LE, Vadera S, Bulacio J, Najm I, Bingaman W. Surgical outcomes in patients with extratemporal epilepsy and subtle or normal magnetic resonance imaging findings. Neurosurgery 2013;73(1):68-77.

49. Barkovich AJ, Kuzniecky Rl, Jackson GD, Guerrini R, Dobyns WB. A developmental and genetic classification for malformations of cortical development. Neurology 2005;65(12):1873-87.

50. Abdel Razek AA, Kandell AY, Elsorogy LG, Elmongy A, Basett AA. Disorders of cortical formation: MR imaging features. AJNR Am J Neuroradiol 2009;30(1):4-11.

51. Barkovich AJ, Guerrini R, Kuzniecky RI, Jackson GD, Dobyns WB. A developmental and genetic classification for malformations of cortical development: update 2012. Brain 2012;135(Pt 5):1348-69.

52. Kuzniecky RI, Barkovich AJ. Malformations of cortical development and epilepsy. Brain Dev 2001;23(1):2-11.

53. Stefan H, Nimsky C, Scheler G, Rampp S, Hopfengärtner R, Hammen $\mathrm{T}$, et al. Periventricular nodular heterotopia: A challenge for epilepsy surgery. Seizure 2007;16(1):81-6.

54. Koh S, Jayakar P, Dunoyer C, Whiting SE, Resnick TJ, Alvarez $L A$, et al. Epilepsy surgery in children with tuberous sclerosis complex: presurgical evaluation and outcome. Epilepsia 2000;41(9):1206-13.

55. Blumcke I, Aronica E, Urbach H, Alexopoulos A, Gonzalez-Martinez JA. A neuropathology-based approach to epilepsy surgery in brain tumors and proposal for a new terminology use for long-term epilepsy-associated brain tumors. Acta Neuropathol 2014;128(1):39-54.

56. Thom M, Blümcke I, Aronica E. Long-term epilepsy-associated tumors. Brain Pathol 2012;22(3):350-79.

57. Urbach H. MRI of long-term epilepsy-associated tumors. Semin Ultrasound CT MR 2008;29(1):40-6. 